\title{
High School Dropout, Resource Attainment, and Criminal
}

\section{Convictions}

\author{
Olof Bäckman \\ Swedish Institute for Social Research \\ Stockholm University \\ Sweden \\ olof.backman@sofi.su.se
}

\begin{abstract}
Objectives: To examine the effect of high-school dropout on subsequent criminal convictions and how post-dropout resource attainment in terms of education and employment may modify such an effect. Methods: Propensity score matching (PSM) using administrative register data covering two full Swedish birth cohorts is employed to assess the effect of dropout on convictions. Event history analysis is used to examine the modifying effect of subsequent resource attainment. Results: The PSM analysis reveals an effect of dropout on convictions for men, whereas no evidence of such an effect is found for women. Returning to school after dropout significantly reduces the crime-inducing effect of dropout among men. Finding occupation after dropout also reduces the risk for criminal conviction, but does so independently of the effect of dropout. Conclusion: Since resource attainment after the dropout event modifies the effect on criminal convictions it is concluded that policies such as life-long learning strategies promoting opportunities for a "second chance" may, besides their intended consequences, also have crime preventive side effects.
\end{abstract}

Keywords: high-school dropout, resource attainment, criminal convictions, propensity score matching, event history analysis

\section{Funding}

This research was supported by the Swedish Research Council for Health, Working Life and Welfare (Forte) [2011-0344].

\section{Acknowledgements}

The author thanks Susanne Alm, Felipe Estrada, Anders Nilsson, three anonymous reviewers and the editor of the JRCD for valuable comments on previous versions of this article.

This article was first published as:

Bäckman, Olof (2017) 'High School Dropout, Resource Attainment, and Criminal Convictions'. Journal of Research in Crime and Delinquency, 54(5): 715-749. doi.org/10.1177/0022427817697441 


\section{Introduction}

The link between school failure and life course failure is well established in the research literature. The risk not only for outcomes such as poverty, social exclusion, and ill health but also for crime and delinquency is dramatically higher among youth who exit education before having reached an upper secondary/high school diploma. Sweeten, Bushway, and Paternoster (2009) reported that in the U.S. high school dropouts are more than 70 percent more likely to be unemployed than high school graduates and that their annual income is on average substantively lower than that of graduates. Their health is worse and, not least, they commit more crime. These observations from the U.S. are in all important respects repeated in Europe (Eurofound 2012). For example, in Sweden high school dropouts are much less likely to be able to support themselves from market income, they have a mortality risk three times that of graduates, and are five times as likely to have been sentenced to prison by the age of thirty (Bäckman and Nilsson 2013).

Although the claim that there is a link between school dropout and criminal behavior is uncontested, the causal direction of this relationship is less evident. Crime and delinquency are known to increase the risk for school dropout, which in turn may promote further delinquent behavior. Sweeten, Bushway, and Paternoster (2009) have made the most serious attempt to date at isolating the effect of high school dropout on subsequent criminality in the U.S. The general conclusion from that study was that there is no such effect, except a small crime-inducing effect in some very specific cases (see below).

The purpose of this paper is to revisit the issue of an independent effect of high school dropout on criminal behavior. In a sense, the paper takes off where Sweeten and colleagues stopped and follows their recommendation to use matching methods to reanalyze this relationship (Sweeten, Bushway, and Paternoster 2009: 77). However, the paper also expands the analysis to the issue of what happens after dropout in terms of resource attainment and how that is linked to continuation and disruption of criminal careers. Thus, by means of propensity score matching, the paper tries to answer the question, "Is high-school dropout independently linked to subsequent criminal behavior or are both just part and parcel of an already unfavorable life career?" On the basis of the result from the matching analysis, we 
turn to the question, "What role does resource attainment after dropout play for the dropout-crime link?" This is analyzed by means of event history analysis.

\section{Education, school attendance, and delinquency: previous research}

The bulk of previous research on the link between educational achievement and crime are-explicitly or implicitly—concerned with the causal direction from education and/or school attendance to crime. Most of the more ambitious studies in this regard are by economists exploiting experiment-like situations. For example, Machin, Marie, and Vujić (2011) analyzed the effect of a school reform which increased the age students left school in England and Wales and found a significant reduction of property crime as a result of the reform. Hjalmarsson, Holmlund, and Lindquist (2015) evaluated the effect of the increase from seven to nine years of compulsory schooling in Sweden on the risks for convictions and incarceration, both of which were substantially reduced. Meghir, Palme, and Schnabel (2012) analyzed the same reform and also found a spillover, crime-reducing effect on the offspring of those actually targeted by the reform. The authors attributed these results to increased household resources and better parenting. In the U.S., Jacob and Lefgren (2003) and Luallen (2006) estimated the incapacitation effect of schools using information on teachers-in-service days and teacher strikes, respectively, and found reductions of property crime rates but increases of violent crime on school days. Similar results were obtained by Berthelon and Kruger (2011), who analyzed the effect of increasing the length of school days in Chile. Åslund et al. (2015) found an incapacitation effect on property crime from a trial period in which vocational tracks in upper secondary school were increased in length from two to three years in some Swedish municipalities. However, they found no effect on violent crime and they found no long-term effects.

Other, more variable-oriented approaches include Kim and Clark (2013) who used propensity score matching (PSM) techniques to isolate the effect of educational attainment on criminal behavior in data from New York State. However, these authors did not analyze high school education but the effect achieving an in-prison college education has on recidivism. They found a small but significant reduction of the risk for recidivism in achieving a college education while incarcerated. Analyzing 
four waves of the U.S. National Longitudinal Survey of Youth (NLSY), Mowen and Brent (2016) showed how school suspension significantly increases the odds of arrest. Aaltonen, Kivivuori, and Martikainen (2011) analyzed the hazard of criminal conviction (theft, violence, and driving under the influence of alcohol) in a large sample of Finns and found an independent crime-reducing effect of graduating from high school on the risk for criminal conviction, controlling for a range of potential confounders. Bäckman and Nilsson (2011) found, in a structural equation model on Swedish birth cohort data, that poor educational achievement in adolescence increases the risk for "deviant behavior" (substance abuse and criminality), which in turn increases the risk for educational failure in early adulthood. Savolainen et al. (2013), using Finnish data, identified adolescent educational marginalization as a key factor linking childhood socioeconomic status to the risk of criminal offending in early adulthood.

Of studies engaged with the opposite causal direction, one of the most prominent analyses is that by Kirk and Sampson (2013), in which PSM was employed to isolate the effect of juvenile arrests on the risk of dropping out of high school and on the chances of college enrollment among Chicago students. They found a large and robust effect of arrests on the high school dropout risk and a significant effect on four-year college enrollment. Sweeten (2006) and Hjalmarsson (2008) obtained similar results on nationally representative U.S. data. However, Hjalmarsson's results suggest a more robust effect of incarceration than of arrests.

Sweeten, Bushway, and Paternoster (2009) listed a number of studies explicitly focused on the effect of school dropout on criminal behavior. The results from these are mixed. Some found that criminal offending declines after dropout (e.g., Elliot and Voss 1974; LeBlanc and Frechette 1989), while others, with longer follow-ups, found increasing crime rates after dropout (e.g., Bachman and O’Malley 1978; Polk et al. 1981). Some studies emphasize that the reason for dropping out of school may influence subsequent delinquency. In one of these, Jarjoura (1993) utilized the (NLSY) and distinguished between various reasons for dropping out of high school and between various types of offences (violence, theft, and selling drugs). The analyses included controls for a wide range of potential confounders, including previous arrests. He found that the reason for dropping out matters for the link between dropout and crime. For example, dropping out because of pregnancy, getting 
married, or dislike of school was linked to increased risks for violent offending (net of controls) whereas dropping out because of expulsion or for "other" reasons increased risks for theft and selling drugs. In a later article, Jarjoura (1996) specified his analyses by examining whether the relationship between dropout and crime was conditioned by socioeconomic origin. In some instances, it was. Dropping out for school reasons or for personal reasons increased the risk for violent offending among upper-status youth, while dropping out for economic reasons reduced the risk for theft offences among lower-status youth.

Sweeten, Bushway, and Paternoster (2009) suggested that the identity associated with expected destinations after dropout also have implications for the dropout-crime link. For example, dropouts who expect to move on to positive identities such as permanent employment or marriage would not be at a greater risk for criminal activity. However, when fitting quasi fixed-effects models for controlling away selection factors for dropout and crime, they found virtually no support for the hypothesized relationships. The only instance in which some support was found was an indication that the small group of males who drop out of school for economic reasons decrease their delinquency, albeit only for a short period of time.

Thus, to summarize, it seems evident that in a broad sense the link between education and crime is strong whereas the evidence of a causal effect of high school dropout on crime is mixed. With regard to education in general, a causal effect on crime can be disputed. The evidence of an incapacitation effect of school on property crime seems fairly robust whereas the longer term "human capital effect" is more difficult to establish when sophisticated methods for handling selection are used. The fact that the most serious attempt hitherto to isolate the effect of dropout on crime (Sweeten, Bushway, and Paternoster 2009) failed to do so could suggest that the case thereby should be closed. However, not even these authors were ready to do so. They pointed to the importance of future research focusing on the actual post-dropout experience (as opposed to the expected destination). With the data available for the analyses in this article, we are able to follow up on dropouts a couple of years after the dropout event, making it possible to identify actual destinations and resource attainment during the postdropout period. The analysis focuses on the effect of finding a foothold in either the labor market or in 
education. Thus, we are also able to account for the fact that many dropouts re-enter high school (“stopouts"; see Sweeten, Bushway, and Paternoster 2009).

\section{Theoretical considerations: social control, strain, and resource attainment}

The theoretical starting point of most studies by criminologists on the dropout-crime link has been strain theory and/or social control theory (e.g., Jarjoura 1993; Sweeten, Bushway, and Paternoster 2009).

Briefly put, social control theory (Hirshi 1969) suggests an increase in delinquent behavior as a consequence of dropping out. This is because individuals' natural inclination to criminality is inhibited by social bonds, and for a teenager school would be among the most important providers of such bonds. Thus, all else being equal, dropping out would result in reduced social bonds and, hence, criminal behavior would increase. Sampson and Laub (1997) put much less emphasis on the inclination to commit crime in their "age graded theory of informal social control". Nevertheless, this is in many senses a development of Hirshi's original, emphasizing how providers of social bonds (e.g., family, school, employment) change across the life course, thus claiming that if the social bonds in school are replaced by bonds in another setting — such as the workplace- the probability of committing crime is again inhibited. In a similar fashion, Sweeten, Bushway, and Paternoster (2009) hypothesized that if an individual after dropping out moves on to a new positive social identity, such as "worker" or "parent," new social bonds are likely to emerge that again will reduce the risk for delinquent behavior. However, if an individual after dropping out becomes, for example, long-term unemployed, no new positive social identity or social bonds will be formed and, hence, the risk for delinquent behavior will increase. As already noted, Sweeten, Bushway, and Paternoster (2009) found only limited support for this position. However, the crime-reducing effect of school attendance found in several of the studies referred to above points in the direction of social control theory. Nevertheless, some findings in this vein of research also speak against the theory, such as the finding that it is primarily property crime which is reduced by school attendance whereas violent crime either increases or is not affected at all. 
Strain theory, too, suggests an increase in criminality after dropping out of school. However, here the mechanisms are different. Basically, Merton's $(1938 ; 1968)$ original work suggested that it is the frustration produced by a mismatch between available means and aspirations that induce criminal behavior. Thus, the theory claims that the less the means, the higher the inclination to commit crime, provided aspirations are fairly similar across groups, and in fact they seem to be (Alm and Estrada 2016). Obviously, this fits well with one of criminology's most stable facts: the negative correlation between criminal behavior and socioeconomic status.

Another school of thought which also fits well with this stable fact is the resource perspective and the life course theory of cumulative advantage and disadvantage. In many respects, this perspective is similar to strain theory, primarily in the sense that it emphasizes shortage of means/resources as the prime mover of the relationship between, in this case, school dropout and subsequent criminal acts.

Life course theory (Elder, Kirkpatrick Johnson, and Crosnoe 2003) posits that individuals construct their own life course through their choices and actions, but within the constraints of historical and social circumstances. People are regarded as active agents whose access to resources and capacity to make use of them determine their levels of opportunity and chances in life (Erikson and Åberg 1987). For instance, poverty during childhood affects educational achievement, health outcomes, and delinquency in adolescence, which in turn affect the risk for low paid jobs, unemployment, and, ultimately, social exclusion in adulthood (Bäckman and Nilsson 2011). Available resources determine the level of opportunity at different stages during the life course. Thus, the mechanism suggested here is the mere number of alternative pathways: the more narrow the range of opportunities (which in turn is determined by resource availability) people are exposed to, the more likely that they will end up in criminal activity. Such a process, in which each case of resource deficiency or disadvantage leads to additional negative consequences, has been labelled "cumulative continuity" (Sampson and Laub 1997) or "cumulative disadvantage" (e.g. Dannefer 2003; DiPrete and Eirich 2006). Obviously, this school of thought is easy to combine with strain theory, by suggesting that the reason why fewer opportunities lead to an increased inclination to commit crime is the frustration created by comparing one's life chances to others with a greater number of possible pathways. 


\section{Dropout, Resources, and Delinquency}

Sweeten, Bushway, and Paternoster (2009) implicitly point in the direction of the cumulative disadvantage and resource perspectives when they comment on the finding that the observed firstorder correlation between delinquency and dropout is driven by time-stable differences between those who drop out and those who do not by suggesting that "concern about the event of dropout may be misplaced. Instead attention must be focused on the process that leads to dropout and criminal involvement ...” (p. 77). However, the present article takes a step further by directing particular attention to the importance of actual resource attainment after dropout. Thus, it is argued in accordance with Sweeten, Bushway, and Paternoster that the post-dropout destination is indeed important for the dropout-crime link, but not primarily because of the new identity and the new social bonds reached, but rather because of the resources linked to these destinations. We concentrate on the resources created by labor market attachment, participation in education, and graduation from high school (upper secondary).

We claim that when a young person drops out of school, a valuable resource is withdrawn. In Sweden, as in most other Western countries, educational failure is a strong predictor of precariousness - for example, social exclusion — across the life course (Bäckman and Nilsson 2011; 2016). In a recent government report, school failure was pointed out as the single most important predictor for inactivity (i.e., participating in neither employment nor education) among Swedish young adults during the 2000s (SOU 2013: 74; see also Bäckman et al. 2015).

In a life course perspective, the withdrawal of a resource (e.g., a high school diploma) has longterm implications unless the loss is compensated for by other forms of resources or the lost resource is regained. However, if a resource is lost at one point in time, it will put that person in a worse position than those who have gained the same resource but otherwise are at the same resource level, simply because the available opportunities will be fewer. For example, if someone drops out of school but manages to find a job his or her prospects will still be poorer relative to those of the workmates who did not drop out, but compared to fellow dropouts who did not find a job, he or she will be better off. 
Thus, the prediction we make from these theoretical perspectives is that high school dropout increases the risk of committing crimes. However, regarding what happens after dropout, the predictions differ slightly. Thus, we firstly hypothesize that (H1) high school dropout increases the risk of offending. Secondly, with reference to the example in the previous paragraph, from both strain theory and the resource perspective, we would expect that $(\mathrm{H} 2)$ being occupied (finding a job or being in education) reduces the risk of offending, but has no implications for the effect of dropout on crime. On the other hand, a competing hypothesis would claim that if new social settings, such as a work place, create new social bonds which replace those lost from dropping out of high school, we would instead expect, according to social control theory, that (H3) being occupied reduces not only the risk of offending, but also the effect of dropout on crime. Finally, put in the context of life courses, the resource perspective and-indirectly - the strain theory claim that resources lost along the way can be regained. Thus, we expect that $(\mathrm{H} 4)$ if the lost educational resource among dropouts is regained, the initial dropout effect disappears or is at least heavily reduced.

\section{The Swedish context}

This section briefly describes three societal areas in Sweden of importance for the topic of the present article: youth crime and the institutional setup for societal reactions; the educational system, with special focus on the upper secondary level (i.e., high school); and the social structure in terms of inequality, the welfare state, and the youth labor market.

\section{Youth Crime and Societal Reactions}

There is no separate juvenile court system in Sweden. All youths whose cases go to court are thus dealt with by the same district courts that deal with adult offenders. There are a number of different sanctions that may be awarded to youths, ranging from prosecution waivers and summary sanction orders to prison. However, prison sentences for youth at 15-20 years of age are extremely rare. The most frequent reactions to crime in these ages are prosecution waiver and summary sanction order awarded for minor crimes. Although prosecution waivers and summary sanction orders do not pass 
through court, they are still registered as convictions since the question of guilt is regarded as settled (Shannon et al. 2014).

\section{The Educational System}

Swedish compulsory school is nine years long. The standard age for finishing is 16 . High school is voluntary but after compulsory school nearly all students (98-99 percent) move on to the upper secondary level ("Gymnasieskola" in Swedish; hereafter "high school”). High school education is a legislated right. However, access to the regular national programs is restricted. The regulations which applied to the cohorts in focus here implied that those who did not meet the requirements for access to a national program were offered a slot in the "individual program," which aimed to prepare students for a transfer to one of the national programs. In each birth cohort, 5-10 percent were enrolled in the individual program. Since this program picked up less motivated students and students with lower cognitive ability, dropout rates were particularly high (around 75 percent in each cohort). The national programs contain both vocational and academic tracks. For the cohorts in focus, dropout rates in vocational tracks were about 25 percent and in academic tracks around 13 percent (at a seven year follow-up; Bäckman et al. 2015). Approximately half of all dropouts manage to achieve a high school diploma by re-entering school (Bäckman et al. 2015). The national programs are three years long.

\section{Inequality, Welfare State, and Labor Market}

The comparatively low degrees of income inequality and relative poverty rates have long been a salient feature of Sweden and the other Nordic countries (e.g., Kautto et al. 1999). In the late 2000s, the Swedish Gini coefficient ${ }^{1}$ of equivalized disposable household income was 0.26 . The corresponding figure for the U.S. was 0.38 and the OECD average was 0.31 (OECD 2011: 45). The economic downturn of the early/mid 1990s struck Sweden particularly hard, with a rapid increase of unemployment. Youths were a group particularly hard hit by the unemployment crisis. The youth unemployment rate increased by a factor of six over the course of a few years: from 3.0 percent in 1990 to 18.1 in $1993 .^{2}$ Starting during the latter half of the 1990 s, the Swedish economy recovered surprisingly quickly, but unemployment figures have never returned to pre-crisis levels. Thus, Sweden 
still struggles with comparatively high unemployment rates, among youths in particular. ${ }^{3}$ Moreover, those who left school early constitute a group identified as experiencing particularly serious difficulties in finding a foothold in the labor market during the 2000s (SOU 2013: 74).

Despite these difficulties, Sweden is still among the countries with the lowest levels of inequality. Inequality of opportunity, as measured by intergenerational correlations of income, seems to be low as well, at least as compared to the U.S. (Björklund and Jäntti 1997; Richter 2016: 98). So, if cumulative disadvantage theory is correct and if it is true that welfare state arrangements may counteract its proposed mechanisms, for instance, by redistributing resources and thereby reducing inequality of both outcomes and opportunities, we could claim that Sweden provides a conservative test case.

\section{Methodological Considerations: data, measurements, and analytical strategy}

\section{Data and Measurements}

Available data comprise all persons born in 1980 and 1985 who were resident in Sweden at the age of $16(\mathrm{~N} \approx 200,000)$. The data extend through the year 2010 and have been compiled by combining information from Statistics Sweden's LISA database, the In-Patient Discharge Register at the National Board of Health and Welfare, the Convictions Register at the National Council for Crime Prevention, and student registers from the National Agency of Education (see Bäckman et al. 2014). The data set includes information on criminal convictions, incomes, school results, educational level, hospital care (diagnoses), and demographic variables. Much of this information is also available for the cohort members' parents.

Thus, registered convictions are used for measuring criminal activity, which means that to be included in the data a criminal act must become known to the judicial system and the question of guilt must have been settled, either by a court or, in the case of prosecution waiver and summary sanction orders, by a prosecutor. Compared to self-reported crime, registered convictions will on average include a greater share of more serious crime, but petty crime still dominates (Shannon et al. 2014). On the other hand, the fact that the information comes from public records virtually eradicates the 
issue of non-response, a problem which can be particularly challenging when analyzing marginalized groups using survey data. Swedish police and prosecutors are bound by the legality principle meaning they must arrest and/or prosecute whenever they suspect a crime has been committed, but conviction rates across cohorts may still depend on e.g. police activity and the inclination of the public to report crime to the police (von Hofer and Lappi-Seppälä 2014). However, this is unlikely to change much between two cohorts who only differ by five years of age, as in our analyses. Nevertheless, cohort membership is included as a variable in the initial logit regressions.

As mentioned above, nearly all students who graduate from compulsory school move on to high school at the age of 16 - that is, in 1996 and 2001 for the two cohorts, respectively. For reasons of privacy, data do not include actual birth dates (only year of birth), which means we do not know the day individuals turned 15 and became criminally responsible. For this reason, we start counting convictions from January 1 of the year they turn 16. In most cases, conviction data include the date of the crime; in those cases for which this information is missing, the crime date has been set equal to the conviction date. ${ }^{4}$ For the sake of simplicity, the date of crime has been recoded to the month of crime.

School data include information about whether a person is registered as a high school student, what program, and what educational year he or she is in, in October each year. This information is used to identify dropouts. Someone who is registered as a student one year but not the year after is coded as dropout, provided no diploma has been gained. To enable matching, a "dropout window" corresponding to October year 2 through October year 3 was established. This means that in the analyses dropouts in this period will be compared to non-dropouts during the same period. A total of 3,266 male students and 3,198 females dropped out in this observation window. A total of 101,706 males and 96,562 females were under risk for dropout, i.e. they were registered as high-school students in October year 2. An important reason for choosing this particular observation window is that we need some time after January of the year cohort members turned 16 to pass in order to be able to measure convictions also before dropout. One consequence of this, of course, is that those 1-2 percent who never start high school and dropouts in year 1 of high school are not included in the analyses, and that dropouts after the dropout window are not treated as dropouts. We know that the earlier the dropout, the poorer the prospects for certain events, such as finding a job (Bäckman et al. 
2015). Since we both exclude a group with poorer prospects from the dropout category and define a group of actual dropouts with better prospects as non-dropouts, the implications of this for the findings are that we probably underestimate the effect of dropout on crime slightly. However, we do include the high school graduation as a time-varying covariate in the final event history analyses, which will capture both later dropouts and "stopouts", that is, dropouts who return and finally graduate.

As will be further described below, the first step of propensity score matching is a logit (or probit) regression in which the log odds for "treatment" —in this case, dropout during the dropout window—is the dependent variable. This regression analysis should include as many potential predictors as possible (e.g., Khandker, Koolwal, and Samad 2010). Here the following variables are included: the average monthly conviction rate prior to the dropout window divided into two variables, one covering the first 12 months from January of the year the cohort member turns 16, and the other covering the remaining 9 months before the dropout window; final grades from compulsory school divided into four groups (low, medium, high, and no information); family type of the household the cohort member lived in at age 16 (single-parent household or not); low parental educational level (lower secondary school at the most); ethnic background (born in Sweden and both parents born in Sweden; born in Sweden and one parent immigrant; immigrated before the age of 13; immigrated after the age of 12); means-tested social assistance received by parents when the cohort member was 8-17 years of age; an indicator of parent's custodial sentence when the cohort member was 0-17 years of age; a dummy variable indicating whether the cohort member ever stayed in a hospital before the dropout window; birth cohort; high school track, separated into individual program, academic programs, and vocational programs.

The aim of including these predictors is to cover important clusters of life course risk factors before the dropout window. The factors cover socio-demographic background factors, social problems in the family of origin, school results and school choice, health, and criminality, and are entered as dummy variables in the regression models (see table A1 and A2 in the appendix). Factors measuring aspects of these clusters have been shown to fit well with a notion of cumulative disadvantage where disadvantage is a function of previous disadvantages (Bäckman and Nilsson 2011). 
The final step of the analyses is an event history regression analysis in which only the matched sample from the PSM is used to estimate the effect of resource attainment after the dropout window on the hazard rate of further convictions. Since we use the matched sample, we need not include any of the independent variables from the initial logit regression. Instead we include only three covariates in these models. Firstly, we include a dummy variable indicating dropout or non-dropout during the dropout window. Secondly, we include a time-varying covariate indicating whether or not the cohort member achieved a high school diploma, either by returning to regular high school or by turning to adult education. The third factor is a time-varying covariate indicating labor market attachment. It is divided into four categories: the core labor force (CLF), capturing those with enough labor market earnings to support themselves during a year; unstable labor force (ULF), capturing those with some earnings though less than the CLF; students, which captures those registered as students and earning less than the CLF; and inactive, capturing those with virtually no labor market income who are not registered as students. ${ }^{5}$ Both of these time-varying covariates build on information aggregated by year whereas the outcome (conviction) in these analyses is measured on a monthly basis. Thus, we need to decide on a month in which any change in these factors occurs in data. Any such decision is bound to be arbitrary and here changes are set to June of the year a change occurs.

\section{Analytical Strategy}

To isolate the effect of dropout on crime, PSM is employed. To perfectly assess the effect of dropout on the risk of future convictions, we would have needed to randomly assign individuals to dropout status. Since this is not possible, we instead apply PSM in order to produce comparable groups of dropouts and non-dropouts. With PSM, we estimate the probability (propensity score) of dropping out during the dropout window by means of logistic regression using the observed characteristics listed above. The propensity score obtained is then used to match the "treatment group" (i.e., dropouts) with "untreated" social twins who, based on the propensity score, were predicted to drop out but did not.

There are a number of alternative methods for matching. For the analytical strategy outlined in the present article the most straightforward technique would be 1-to-1 nearest neighbor matching, in which the nearest neighbor, in terms of propensity score, is chosen as a match. However, the most 
important criterion for choosing matching algorithm is that the observed covariates are balanced after matching (see below). Thus, there is need to evaluate other matching techniques as well, to ensure covariate balance.

Nearest neighbor matching is often performed using a caliper, which involves specifying a limit for how much the propensity score can differ within a pair. The drawback of 1-to-1 nearest neighbor matching with caliper is that the use of the technique involves a risk of losing observations, which in some instances makes the results less efficient. Given the fairly large sample used in this study, however, this risk is reduced. ${ }^{6}$

The propensity score is a "balancing score," which refers to the need for a similar distribution of observed covariates between treated and untreated subjects who have similar values on the propensity score. This assumption needs to be carefully investigated to ensure the comparability of cases (Austin 2011)

The most important output produced by PSM methods is most commonly the average effect of treatment on the treated (ATT), which is simply the outcome difference between the matched treatment and non-treatment groups (see Becker and Ichino 2002).

Despite the convincing results reported in the seminal article by Rosenbaum and Rubin (1983), indicating that PSM does a very good job of mimicking truly randomized designs, criticism has been directed at the belief that this method can replace randomization. Not least, it has been shown that PSM is sensitive to the set of variables included in the regression analysis used to estimate the propensity scores (Smith and Todd 2005). Thus, there is always a risk that the conditional independence assumption (CIA) is violated, that is the assumption that there are no unobservables that can bias the probability of treatment and the effect of treatment on outcome. However, there are techniques available to simulate potential confounders and how these could affect the robustness of results (e.g., Ichino, Mealli, and Nannicini 2008; Nannicini 2007).

The outcome in the PSM analyses is a dummy variable indicating any conviction during a followup period of 26 months after the dropout window. This is a static outcome which does not capture processes after exposure. However, an important contribution of this study is the emphasis of postdropout events. In order evaluate how destinations and resources gained after dropout impact on the 
risk of offending, event history analysis on the matched sample is utilized. In event history analysis, we analyze the risk (hazard) across time under risk of failure (Blossfeldt, Golsch, and Rohwer 2007). In this study, failure is the first criminal conviction and time under risk (exposure time) is the time passed since the ending of the dropout window. The piecewise constant exponential model is used to estimate the hazard rate. In this model, exposure time is included as a dummy variable for each time period, in which the hazard rate is assumed constant, but is allowed to vary between the specified time periods. In the analysis below the baseline hazard is allowed to vary every second month during the first year, every fourth month during the second year, and thereafter every sixth month. The follow-up period ranges from the end of the dropout window through the year the cohort member turns 24 . Observations with no conviction by December of this year or who emigrate or die prior to that are right-censored.

\section{Results}

\section{High school Dropout and Criminal Convictions: Descriptives}

The graphs in Figure 1 show the monthly conviction rates among dropouts and non-dropouts before and after the dropout window in the two birth cohorts in the data. In these graphs, dropouts are defined as those who dropped during the "dropout window." Overall conviction rates are greater among dropouts than among non-dropouts for both females and males. The monthly rates are lower after the dropout window than before it for both groups and both sexes, as we would expect from the usual age-crime curve which in Sweden peaks around age 17 (Wikström 1990). However, since we look at monthly conviction rates, the pattern for women is strikingly unstable despite the fact that the graph shows three-year moving averages. This is, of course, due to the low conviction rate among women. On average, the absolute decline is greater among dropouts, whereas the relative decline is greater among non-dropouts.

- Figure 1 about here - 


\section{High school Dropout and Criminal Convictions: Propensity Score Matching}

Taken together, the graphs in Figure 1 underscore the importance of taking selection to the dropout group into account, the initial conviction rate in particular, when evaluating its effects. As discussed above, the approach chosen to accomplish this here is PSM. These analyses are run separately for men and women. Since the logit regression models are merely tools to produce propensity scores, the results from the regression analyses are not reported, but are available upon request. Briefly stated, however, the regression results generally point in the expected direction. Factors indicating resource deficiency prior to the dropout window predict a higher propensity to drop out. There are some gender differences. Means-tested social assistance received by parents is a more important predictor of men's dropout risk whereas ill health, as indicated by hospital stays, cohort membership, and high school track, are more important predictors for women's dropout risk. Previous criminal convictions are particularly strong predictors for both male and female dropout risks, with odds ratios around four.

The aim of the PSM analyses is to isolate the effect of high school dropout during the dropout window on subsequent conviction risks. Here 1-to-1 nearest neighbor matching is employed. Other matching procedures, such as Kernel and radius matching, produce virtually identical results. All actual dropouts (3,266 males; 3,198 females) resulted in a match within common support (range of common support: .04-.61). ${ }^{7}$

Table 1 shows the result from the PSM analysis for men and women separately. Here the treated (dropouts in the dropout window) are compared with a control group of "social twins" who-with respect to the observed variables included in the regression analysis - are estimated to have a similar propensity to drop out, but did not.

- Table 1 about here -

The outcome in the PSM analysis is the likelihood of criminal convictions during a follow-up period of 26 months after the dropout window. The table shows the difference between the treated and controls, both before and after matching. The difference between unmatched men is particularly high. 
It is heavily reduced after matching, but still statistically significant. The initial difference between unmatched treated and controls among women is less substantive, and after matching the difference is no longer statistically significant. This suggests that dropping out of high school has an independent crime-inducing effect among Swedish young men while no such effect is evident for women. Even though female dropouts have a higher conviction rate than non-dropouts, the dropout event per se does not add to this difference. Other aspects of resource deficiencies and cumulative disadvantage seem more important for the selection of young Swedish women into criminality.

As mentioned above, although matching is based on the predicted probability from the logistic regression, it is assumed that values of the variables included in the regression model are balanced, namely, that they are reasonably equal between the treated and controls. The literature suggests that a percent bias below ten indicates balance (Austin 2011). Tables A1 and A2 in the appendix show that the balance for both men and women is very good. In no case is there a percent bias above five after matching and the variances are virtually identical. None of the alternative techniques referred to above are able to improve this balance. However, the appendix tables show only balance with respect to means and this does not suffice with respect to continuous variables. In these cases it is important to reassure that not only the means are balanced, but the whole distribution (Austin 2009). Although all included covariates are categories operationalized as dummy variables, some of them are constructed on underlying continuous measures. Of these only the variable measuring grades from compulsory school is based on a continuous variable with a range wide enough to require further checks. Thus, further balance checks of this factor were performed, such as quantile-quantile plots and the Kolmogorov-Smirnov test (Austin 2009), which show that balance of the distribution was achieved as well (results not shown; available upon request).

- Figure 2 about here -

The good match is further confirmed by the graphs in Figure 2, showing monthly conviction rates before and after the observation window in the matched male sample. In contrast to what was shown in Figure 1, these graphs show fairly equal crime rates before the dropout window for both men and 
women. The level after the dropout window is substantively lower for non-dropouts through the observation period. This answers to the first hypothesis above, maintaining both a short- and long-term effect of dropout on crime. However, for women, the levels continue to be fairly equal after the dropout window as well, suggesting that the hypothesis must be rejected for females.

Despite the good match indicated by both the balance tables in the appendix and the graphs in Figure 2, the credibility of these results are dependent upon the CIA, that is, that there are no unobservables that can bias the results. Despite the many merits associated with using administrative register data, such as a large $\mathrm{N}$, the longitudinal character, and the absence of non-response, the number of available covariates is fairly limited. This increases the vulnerability to omitted variable bias. Since the result of the PSM is insignificant for women, this concerns only the results from the analysis on men. However, simulations using a technique for evaluating the likelihood of the existence of an omitted variable or a set of omitted variables that could explain away the observed effect of treatment (dropout) on the outcome, suggested by Ichino, Mealli, and Nannicini (2008), indicate that the existence of an omitted variable (or set of variables) with the properties needed to drive the observed effect to zero is unlikely (results not shown; available upon request). It should be noted though that this test account only for the potential impact of categorical variables. It does not take into account properties of continuous potential confounders.

\section{High school Dropout, Resource Attainment, and Criminal Convictions: Hazard Regression}

One aim of the propensity score analysis was to make dropouts and non-dropouts as equal as possible up to the point of dropout. The second step of the analysis is to estimate how post-dropout events impact the risk of criminal convictions. As already mentioned, event history analysis is used for this purpose. Since the PSM rendered significant results only for men, this part of the analyses is only performed for the male portion of the sample. By using only the matched sample, indicators of circumstances before the dropout window are already controlled for and need not be included. Figure 3 shows the estimated baseline hazard rate from a model without covariates. The expected pattern with a declining hazard rate across exposure time prevails. More interesting for the purpose of the present study are the estimates reported in Table 2. Model 1 confirms the result from the PSM analysis by 
indicating an elevated hazard by a factor of 1.54 for dropouts as compared to the matched controls. In model 2, we include a time-varying covariate measuring labor market attachment. The result indicates that being inactive is associated with an elevated hazard of approximately the same magnitude as dropouts in model 1 . Note also that the inclusion of the labor market attachment factor only has limited impact on the effect of dropout. The latter corresponds to the prediction made in hypothesis 2 , that labor market attachment would reduce the crime risk without having any implications for the effect of dropout, whereas hypothesis 3 can be rejected.

- Figure 3 and Table 2 about here -

In model 3, we include a time-varying covariate indicating whether or not a high school diploma was gained during follow-up. The effect is salient: the hazard for being convicted among those who gained a diploma during follow-up is less than half of that of those who did not. Moreover, the effect of dropout on crime is substantively reduced, which corresponds well with the prediction maintained by hypothesis 4 above. Finally, in model 4 , the two time-varying covariates are included simultaneously, but that does not have any implications for the findings in the previous models.

Thus, the event history analysis provides some support for all perspectives discussed above, but in the only instance in which social control theory on the one hand and the resource perspective and strain theory on the other render diverging predictions (hypotheses 2 and 3), the results seem to lend support primarily to the resource perspective and strain theory.

\section{Discussion}

The main result from the analyses in this article is that high school dropout has a crime-inducing effect for Swedish men born in the 1980s. However, for the corresponding group of women, no such effect can be discerned. For young women, the first-order correlation between dropout and crime is instead driven by time-invariant differences and differences in resource accumulation before dropout. 
For men too, a large part of the first-order correlation is driven by factors measured before dropout, but here high school dropout appears to have an independent effect on the risk of subsequent offending. However, the main contribution of this study to the field is the analyses on how postdropout destinations and resource attainment impact both the conviction risk per se and mediate the effect of dropout on criminal behavior. Although no causal claims are made in this part of the analyses, the results clearly show that finding a foothold in the labor market or in education, and whether or not a high school diploma is achieved after dropout have clear implications for subsequent criminal conviction risks. Those finding an occupation reduce their conviction risk, and gaining a high school diploma nearly eradicates the initial risk induced by dropping out.

These findings are all the result of an effort to test a couple of hypotheses derived from social control theory, strain theory, and the resource perspective. Taken together, all perspectives receive some support in the analyses. All predict a crime-inducing effect from dropout and all predict that being occupied, either in the labor market or in education, reduces the conviction risk as well. However, the preoccupation with social bonds in social control theory suggests that adding resources would not be so important unless the resources come with new social bonds. The fact that postdropout graduation significantly reduces the conviction risk independently of labor market attachment, and that the effect of dropout is substantively reduced when this indicator is included in the regression model, speaks against social control theory. On the other hand, it could be claimed that in order to be able to take up high school studies after a dropout, some kind of social bonds need to be present, at least with society as a whole in some vague sense.

Thus, the results should not be seen as a rejection of social control theory, only that for this particular question strain theory and the resource perspective might provide better, or at least, more clear-cut explanations. Even more difficult than to distinguish between social control theory on the one hand and the strain and resource perspectives on the other, it is to distinguish between the latter two. With the data available for this study, this is probably not possible. The two perspectives make the same predictions. Strain is more explicit with the active mechanism at the individual level, namely, frustration. The resource perspective instead focuses more on the number of available options. Very simplified, the resource perspective reduces the mechanism to a matter of likelihoods, implying that 
the fewer the number of possible outcomes, the higher the probability of one particular outcome. Of course, reality is more complex, not least because some options are more attractive than others and preferences for one option over the other may vary depending on, for example, social background and context. Regardless of this, the resource perspective cannot on its own explain why a relative shortage of opportunities would lead to crime. Here strain theory may provide one answer: relative deprivation of means to achieve desired goals creates frustration.

However, for all practical purposes, distinguishing between strain theory and the resource perspective may seem pointless. Both perspectives suggest that it is resource attainment which governs the likelihood of a criminal conviction. Thus, the distribution of resources in a society becomes a key factor in crime prevention. As mentioned above, Sweeten, Bushway, and Paternoster (2009) conclude that attention should be focused on those processes that lead to dropout and crime rather than on the actual effect of dropout on crime. This study lends support to that view, since for both men and women most of the difference between dropouts and non-dropouts is explained by previous experiences and resource attainment, although for men high school dropout add to the already elevated risk.

However, it is worth highlighting that the fact that convictions are used as an indicator of criminal activity means that the risk of being detected is an important factor and if dropouts tend to spend more time in criminogenic public environments where the risk of detection is greater, then that could be part of the explanation of the elevated risk of conviction among (male) dropouts. Thus it could be claimed that dropouts not only "reorder(s) short-term situational inducements to crime" (Laub and Sampson 2003:147) but also experience increased risks of being officially processed as criminals by shifting the normal routines of life. Register data provide no information that could help us investigating that issue. For that other types of data are needed, but the fact the highest conviction risk is found among inactive dropouts indicates that this interpretation might hold too. On other hand, a large part of offences committed by youths are committed in connection to the school environment and here both the detection risk and the willingness to report crimes are high. 
Independent of this potentially alternative interpretation of the dropout effect is the claim that the most important implication of this study is the significance of a "second chance". The availability of an opportunity structure, which provides those who fail at one point in time with a chance to repair the damage at a later point in time, appears desirable. In fact, the Swedish system for a second chance to achieve a high school diploma seems to work comparably well and is an important explanation to why Swedish high school dropouts run a much lower risk for labor market exclusion than dropouts in neighboring Norway (Bäckman et al. 2015). As mentioned above, about half of those who drop out achieve a diploma within a couple of years. Thus, judging from the results presented here, an unintended consequence of Sweden's lifelong learning strategy might be a small but significant reduction of crime among young males.

The vicious circles described by the cumulative disadvantage theory, in which each case of resource deficiency leads to additional negative consequences, may thus be interrupted by new resource attainment. In that sense, adding resources to a negative life course may serve as a turning point as described by Sampson and Laub (1997).

\section{Limitations}

Another implication of using register based conviction data, in which only crimes known to the authorities and where someone was found guilty are accounted for, is that involvement in petty crime, which remained hidden to the police could potentially trigger dropout, suggesting a reversed causal order. However, across time the likelihood of discovery increases and since conviction histories are included in the PSM analyses this problem is most likely reduced. A second limitation is that despite the apparently good balance reached and that the sensitivity test of the PSM analysis indicates robust results for men, we can never be completely confident that no important factors, predicting both dropout and criminality, have been omitted. In analyses of criminal behavior omitted indicators of personality traits linked to asocial behavior are of particular importance. Such traits are also likely to predict high-school dropout. However, Caliendo, Mahlstedt, and Mitnik (2014) show that the influence of omitted indicators of personality traits in evaluations of labor market policies did have 
strong effects on both treatment and outcome, but still did not impact on the effect of treatment on outcome when labor market histories were included in the PSM. The extent to which these findings from labor economics are generalizable to the field of criminology may of course be disputed, but they do indicate that omitted variables that we know are important need not always flaw our results.

\section{Notes}

\footnotetext{
${ }^{1}$ The Gini coefficient is an often-used measure of income inequality, ranging from 0 to 1 , in which higher values indicate higher levels of inequality.

${ }^{2}$ Statistics Sweden: http://www.statistikdatabasen.scb.se, accessed August 27, 2015.

${ }^{3}$ For the years when the two birth cohorts in the analyses turned 18, 1998 and 2003, the youth unemployment rate (16-24 years of age) was 12 and 10 percent, respectively (http://www.statistikdatabasen.scb.se/, accessed April 14, 2016).

${ }^{4}$ For ages $15-25,8$ percent of convictions lack a date for the crime. Among convictions with a date for the crime, the average time from crime to conviction is 4.6 months ( $\mathrm{sd}=5.7$ ).

${ }^{5}$ This way of measuring labor market attachment using administrative data is inspired by the so-called SELMA model which has been developed for this purpose for the Scandinavian countries (see Bäckman et al. 2015).

${ }^{6}$ The psmatch2 module in STATA was employed to perform PSM (Leuven and Sianesi 2003).

${ }^{7}$ The results presented here are insensitive to the inclusion and exclusion of caliper $(0.5 \mathrm{sd}$ and $0.2 \mathrm{sd}$ of the propensity score).
} 


\section{References}

Aaltonen, Mikko, Janne Kivivuori, and Pekka Martikainen. 2011. "Social Determinants of Crime in a Welfare State: Do They Still Matter?” Acta Sociologica 54:161-81.

Alm, Susanne, and Felipe Estrada. 2016. "Future Expectations, Frustration and Criminality—Classic Strain Theory Revisited.” Manuscript. Department of Criminology, Stockholm University.

Åslund, Olof, Hans Grönqvist, Caroline Hall, and Jonas Vlachos. 2015. "Education and Criminal Behavior: Insights from and Expansion of Upper Secondary School.” IFAU Working Paper 2015:15.

Austin, Peter C. 2009. "The Relative Ability of Different Propensity Score Methods to Balance Measured Covariates between Treated and Untreated Subjects in Observational Studies.” Medical Decision Making 29:661-677.

Austin, Peter C. 2011. "An Introduction to Propensity Score Methods for Reducing the Effects of Confounding in Observational Studies." Multivariate Behavioral Research 46:399-424.

Bachman, Jerald G., and Patrick O’Malley. 1978. Youth in Transition, Volume VI: Adolescence to Adulthood: Change and Stability in the Lives of Young Men. Ann Arbor, MI: University of Michigan Press.

Bäckman, Olof. 2009. "Institutions, Structures and Poverty. A Comparative Study of 16 Countries, 1980-2000.” European Sociological Review 25:251-64.

Bäckman, Olof, Felipe Estrada, Anders Nilsson, and David Shannon. 2014. "The Life Course of Young Male and Female Offenders-Stability or Change Between Different Birth Cohorts?" British Journal of Criminology 54:393-410.

Bäckman, Olof, Vibeke Jakobsen, Thomas Lorentzen, Eva Österbacka, and Espen Dahl. 2015. "Early School Leaving in Scandinavia: Extent and Labour Market Effects.” Journal of European Social Policy 25:253-69. 
Bäckman, Olof, and Anders Nilsson. 2011. "Pathways to Social Exclusion-A Life Course Study." European Sociological Review 27:107-23.

Bäckman, Olof, and Anders Nilsson. 2013. "Unga som varken arbetar eller studerar-olika definitioners betydelse för omfattning, sammansättning och konsekvenser." [Young People not in Employment or Education - the Impact of Various Definitions on Extent, Composition and Consequences]. Pp. 331-246 in Unga som varken arbetar eller studerar-statistik, stöd och samverkan [Young People not in Employment or Education-Statistics, Support and Cooperation]. Final report from the Governmental Inquiry on Youth Not in Employment or Education. SOU 2013:74. Stockholm: Fritzes.

Bäckman, Olof, and Anders Nilsson. 2016. "Long-term Consequences of Being not in Employment, Education or Training as a Young Adult. Stability and Change in Three Swedish Birth Cohorts." European Societies 18:136-57.

Becker, Sacha O., and Andrea Ichino. 2002. "Estimation of Average Treatment Effects Based on Propensity Scores.” The Stata Journal 2: 358-77.

Berthelon, Matias E., and Diana I. Kruger. 2011. "Risky Behavior among Youth: Incapacitation Effects of School on Adolescent Motherhood and Crime in Chile.” Journal of Public Economics 95:41-53.

Björklund, Anders, and Markus Jäntti. 1997. "Intergenerational Income Mobility in Sweden Compared to the United States." American Economic Review 87:1009-18.

Blossfeldt, Hans-Peter, Katrin Golsch, and Götz Rohwer. 2007. Event History Analysis with Stata. London: Lawrence Erlbaum.

Caliendo, Marco, Robert Mahlstedt, and Oscar A. Mitnik. 2014. "Unobservable, but Unimportant? The Influence of Personality traits (and Other Unobserved Variables) for the Evaluation of Labor Market Policies.” IZA Discussion Paper No. 8337. July 2014.

Dannefer, Dale. 2003. "Cumulative Advantage/Disadvantage and the Life Course: Cross-Fertilizing Age and Social Science Theory. Journal of Gerontology: Social Sciences 58B:S327-37. 
DiPrete, Thomas A., and Gregory M. Eirich. 2006. "Cumulative advantage as a mechanism for inequality: A review of theoretical and empirical developments." Annual Review of Sociology 32:271-97.

Elder, Glenn H. Jr, Monica Kirkpatrick Johnson, and Robert Crosnoe. 2003. “The emergence and development of life course theory." Pp. 3-19 in Handbook of the Life Course, edited by Jeylan T. Mortimer and Michael J. Shanahan. New York: Plenum.

Elliott, Delbert S., and Harwin L. Voss. 1974. Delinquency and Dropout. Lexington, MA: D. C. Heath.

Erikson, Robert, and Rune Åberg. 1987. "The Nature and Distribution of Welfare.” Pp. 1-13 in Welfare in Transition. A Survey of Living Conditions in Sweden 1968-1981, edited by Robert Erikson and Rune Åberg. Oxford: Clarendon Press.

Estrada, Felipe, Olof Bäckman, and Anders Nilsson. 2016. "The Darker Side of Equality? The Declining Gender Gap in Crime: Historical Trends and Enhanced Analysis of Staggered Birth Cohorts. British Journal of Criminology. 56:1272-1290.

Eurofound. 2012. NEETS -Young People not in Employment, Education or Training: Characteristics, Costs and Policy Responses in Europe. Luxembourg: Publications Office of the European Union.

Hirshi, Travis. 1969. Causes of Delinquency. Berkeley, CA: University of California Press.

Hjalmarsson, Randi. 2008. “Criminal Justice Involvement and High School Completion.” Journal of Urban Economics 63:613-30.

Hjalmarsson, Randi, Helena Holmlund, and Matthew J. Lindquist. 2015. "The Effect of Education on Criminal Convictions and Incarceration: Causal Evidence from Micro-Data." The Economic Journal 125:1290-1326.

Ichino, Andrea, Fabrizia Mealli, and Tommaso Nannicini. 2008. "From Temporary Help Jobs to Permanent Employment: What Can We Learn from Matching Estimators and their Sensitivity?" Journal of Applied Econometrics 23:305-27. 
Jacob, Brian A., and Lars Lefgren. 2003. "Are Idle Hands the Devil's Workshop? Incapacitation, Concentration and Juvenile Crime.” National Bureau of Economic Research Working Paper 9653.

Jarjoura, Roger G. 1993. "Does Dropping out of School Enhance Delinquent Involvement? Results from a Large-scale Probability Sample.” Criminology 31:149-72.

Jarjoura, Roger G. 1996. "The Conditional Effects of Social Class on the Dropout-delinquency Relationship." Journal of Research in Crime and Delinquency 33:232-55.

Kautto, Mikko, Matti Heikkilä, Bjørn Hvinden, Staffan Marklund, and Niels Ploug. 1999. Nordic Social Policy: Changing Welfare States. London: Routledge.

Khandker, Shahidur R., Gayatri B. Koolwal, and Hussain A. Samad. 2010. Handbook on Impact Evaluation. Quantitative Methods and Practices. Washington, DC: The World Bank.

Kim, Ryang Hui, and David Clark. 2013. "The Effect of College Education Programs on Recidivism: Propensity Score Matching Approach.” Journal of Criminal Justice 41:196-204.

Kirk, David S., and Robert J. Sampson. 2013. "Juvenile Arrests and Collateral Educational Damage in the Transition to Adulthood." Sociology of Education 86:36-62.

Laub, John H., and Robert J. Sampson. 2003. Shared Beginnings, Divergent Lives. Delinquent Boys to Age 70. Cambridge, MA: Harvard University Press.

LeBlanc, Marc, and Marcel Frechette. 1989. Male Criminal Activity from Childhood Through Youth: Multilevel and Developmental Perspectives. New York: Springer-Verlag.

Leuven, Edwin, and Barbara Sianesi. 2003. PSMATCH2: Stata module to perform full Mahalanobis and propensity score matching, common support graphing, and covariate imbalance testing, Boston College Department of Economics, Statistical Software Components. Download: http://ideas.repec.org/c/boc/bocode/s432001.html.

Luallen, Jeremy. 2006. "School's out . . . Forever: A Study of Juvenile Crime, At-risk Youths and Teacher Strikes.” Journal of Urban Economics 59:75-103.

Machin, Stephen, Olivier Marie, and Sunčica Vujić. 2011. "The Crime Reducing Effect of Education.” The Economic Journal 121:463-84. 
Meghir, Costas, Mårten Palme, and Marieke Schnabel. 2012. "The Effect of Educational Policy on Crime: An Intergenerational Perspective.” National Bureau of Economic Research Working Paper 18145.

Merton, Robert K. 1938. “Social Structure and Anomie.” American Sociological Review 3:672-82.

Merton, Robert K. 1968. Social Theory and Social Structure. Glencoe: Free Press.

Mowen, Thomas, and John Brent. 2016. "School Discipline as a Turning Point: The Cumulative Effect of Suspension on Arrest.” Journal of Research in Crime and Delinquency 53:628-653.

Nannicini, Tommaso. 2007. "Simulation-based Sensitivity Analysis for Matching Estimators." The Stata Journal 7:334-50.

OECD. 2011. Divided We Stand: Why Inequality Keeps Rising. Paris: OECD Publishing.

Polk, Kenneth, Christine Adler, Gordon Bazemore, Gerald Blake, Sheila Cordray, Gary Coventry, James Galvin, and Mark Temple. 1981. "Becoming Adult: An Analysis of Maturational Development from Age 16 to 30 of a Cohort of Young Men.” Final Report of the Marion County Youth Study. Eugene: University of Oregon.

Richter, André. 2016. Essays on the Intergenerational Transmission of Disadvantage. Swedish Institute for Social Research, Dissertation Series no. 94. Stockholm: Stockholm University.

Rosenbaum, Paul R., and Donald B. Rubin. 1983. "The Central Role of the Propensity Score in Observational Studies for Causal Effects.” Biometrika 70:41-55.

Sampson, Robert J., and John H. Laub. 1997. “A Life-course Theory of Cumulative Disadvantage and the Stability of Delinquency." Pp. 133-161 in Advances in Criminological Theory, Vol. 7: Developmental Theories of Crime and Delinquency, edited by Terence P. Thornberry. New Brunswick, NJ: Transaction Publishers.

Savolainen, Jukka, Lorine A. Hughes, Tuula M. Hurtig, Hanna Ebeling, and Anja M. Taanila. 2013. "Does Vocational Schooling Facilitate Criminal Offending? A Study of Educational Tracking in Finland." European Journal of Criminology 10:606-22. 
Shannon, David, Olof Bäckman, Felipe Estrada, and Anders Nilsson. 2014. "Youth and Crime in Sweden.” In Oxford Handbooks Online. New York: Oxford University Press.

Smith, Jeffrey A., and Petra E. Todd. 2005. "Does Matching Overcome Lalonde's Critique of Nonexperimental Estimators?” Journal of Econometrics 125:305-53.

SOU. 2013:74. Unga som varken arbetar eller studerar-statistik, stöd och samverkan. [Young People not in Employment or Education-Statistics, Support and Co-operation]. Final report from the Governmental Inquiry on Youth Not in Employment or Education. Stockholm: Fritzes.

Sweeten, Gary. 2006. "Who Will Graduate? Disruption of High School Education by Arrest and Court Involvement." Justice Quarterly 23: 462-480.

Sweeten, Gary, Shawn D. Bushway, and Raymond Paternoster. 2009. "Does Dropping out of Sschool Mean Dropping into Delinquency?" Criminology 47:47-91.

von Hofer, Hanns and Tapio Lappi-Seppälä. 2014. "The Development of Crime in light of Finnish and Swedish Criminal Justice Statistics, circa 1750-2010.” European Journal of Criminology 11: 169194.

Wikström, Per-Olof. 1990. "Age and Crime in a Stockholm Cohort." Journal of Quantitative Criminology 6: 61-84. 


\section{Appendix}

Table A1. Balance Table Men.

\begin{tabular}{|c|c|c|c|c|c|c|c|}
\hline \multirow[b]{2}{*}{ Variable } & \multirow[b]{2}{*}{ Sample } & \multicolumn{2}{|c|}{ Mean } & \multirow[b]{2}{*}{$\%$ bias } & \multirow{2}{*}{$\begin{array}{l}\% \text { red. } \\
\mid \text { bias } \mid\end{array}$} & \multicolumn{2}{|c|}{ Variance } \\
\hline & & Treated & Contr. & & & Treated & Control \\
\hline \multicolumn{8}{|c|}{ Socio-demographic background and year of birth: } \\
\hline \multirow[t]{2}{*}{ Born 1985 (ref:1980) } & Unmatched & 0.524 & 0.507 & 3.5 & & 0.254 & 0.254 \\
\hline & Matched & 0.524 & 0.524 & 0.2 & 94.8 & 0.254 & 0.254 \\
\hline \multirow{2}{*}{$\begin{array}{l}\text { Two parents (ref: } \\
\text { single parent) }\end{array}$} & Unmatched & 0.581 & 0.751 & -36.7 & & 0.240 & 0.190 \\
\hline & Matched & 0.581 & 0.582 & -0.3 & 99.1 & 0.240 & 0.240 \\
\hline \multirow[t]{2}{*}{ Other family type } & Unmatched & 0.016 & 0.005 & 10.8 & & 0.015 & 0.005 \\
\hline & Matched & 0.016 & 0.012 & 3.4 & 69 & 0.015 & 0.012 \\
\hline \multirow{2}{*}{$\begin{array}{l}\text { Low parent educ. (ref: } \\
\text { not low) }\end{array}$} & Unmatched & 0.199 & 0.101 & 27.7 & & 0.158 & 0.092 \\
\hline & Matched & 0.199 & 0.198 & 0.1 & 99.7 & 0.158 & 0.158 \\
\hline \multirow{2}{*}{$\begin{array}{l}\text { Native, both parents } \\
\text { native (ref: immi. age }>12 \text { ) }\end{array}$} & Unmatched & 0.803 & 0.867 & -17.4 & & 0.158 & 0.113 \\
\hline & Matched & 0.803 & 0.807 & -1.2 & 93.3 & 0.158 & 0.158 \\
\hline \multirow{2}{*}{$\begin{array}{l}\text { Native, } \geq 1 \text { parent } \\
\text { Immigrant }\end{array}$} & Unmatched & 0.061 & 0.041 & 8.9 & & 0.058 & 0.041 \\
\hline & Matched & 0.061 & 0.058 & 1.3 & 85.9 & 0.058 & 0.058 \\
\hline \multirow[t]{2}{*}{ Immigration age $\leq 12$} & Unmatched & 0.097 & 0.072 & 9.2 & & 0.085 & 0.068 \\
\hline & Matched & 0.097 & 0.095 & 0.8 & 91.6 & 0.085 & 0.085 \\
\hline \multicolumn{8}{|l|}{ Social problems in parents: } \\
\hline \multirow{2}{*}{$\begin{array}{l}\text { 1-2 years with fam. } \\
\text { SA }^{\mathrm{i}} \text { age } 8-17 \text { (ref: } 0 \text { yrs) }\end{array}$} & Unmatched & 0.502 & 0.748 & -52.5 & & 0.254 & 0.190 \\
\hline & Matched & 0.502 & 0.499 & 0.7 & 98.6 & 0.254 & 0.254 \\
\hline \multirow{2}{*}{$\begin{array}{l}3+\text { years with fam. } \\
\text { SA age 8-17 }\end{array}$} & Unmatched & 0.147 & 0.104 & 13.2 & & 0.130 & 0.092 \\
\hline & Matched & 0.147 & 0.144 & 1 & 92.3 & 0.130 & 0.121 \\
\hline \multirow{2}{*}{$\begin{array}{l}\geq 1 \text { cust. sentence in } \\
\text { parents, age } 0-17\end{array}$} & Unmatched & 0.087 & 0.035 & 21.7 & & 0.079 & 0.034 \\
\hline & Matched & 0.087 & 0.090 & -1.5 & 92.9 & 0.079 & 0.079 \\
\hline \multicolumn{8}{|c|}{ School performance and choice: } \\
\hline \multirow{2}{*}{$\begin{array}{l}\text { Medium grades (ref: low } \\
\text { grades) }^{\mathrm{ji}}\end{array}$} & Unmatched & 0.237 & 0.576 & -73.6 & & 0.179 & 0.240 \\
\hline & Matched & 0.237 & 0.235 & 0.5 & 99.4 & 0.179 & 0.179 \\
\hline \multirow[t]{2}{*}{ High grades } & Unmatched & 0.033 & 0.166 & -45.6 & & 0.031 & 0.138 \\
\hline & Matched & 0.033 & 0.032 & 0.2 & 99.5 & 0.031 & 0.031 \\
\hline \multirow[t]{2}{*}{ Grades, no info. } & Unmatched & 0.040 & 0.012 & 17.8 & & 0.037 & 0.012 \\
\hline & Matched & 0.040 & 0.036 & 2.3 & 87 & 0.037 & 0.037 \\
\hline \multirow{2}{*}{$\begin{array}{l}\text { Vocational track (ref: } \\
\text { academic) }\end{array}$} & Unmatched & 0.462 & 0.510 & -9.6 & & 0.254 & 0.254 \\
\hline & Matched & 0.462 & 0.461 & 0.1 & 98.7 & 0.254 & 0.254 \\
\hline \multirow[t]{2}{*}{ Ind. program } & Unmatched & 0.360 & 0.042 & 86.5 & & 0.227 & 0.041 \\
\hline & Matched & 0.360 & 0.363 & -0.7 & 99.1 & 0.227 & 0.227 \\
\hline Health: & & & & & & & \\
\hline Ever hospital care (ref: & Unmatched & 0.048 & 0.038 & 5.1 & & 0.045 & 0.037 \\
\hline no) & Matched & 0.048 & 0.048 & 0.3 & 94.1 & 0.045 & 0.045 \\
\hline Previous convictions: & & & & & & & \\
\hline Pre-treatment & Unmatched & 0.020 & 0.005 & 40.9 & & 0.002 & 0.001 \\
\hline conv. month 1-12 (ref: 0) & Matched & 0.020 & 0.019 & 3 & 92.6 & 0.002 & 0.002 \\
\hline Pre-treatment & Unmatched & 0.022 & 0.004 & 41.4 & & 0.003 & 0.001 \\
\hline conv. month $13-21$ & Matched & 0.022 & 0.020 & 3.2 & 92.3 & 0.003 & 0.003 \\
\hline
\end{tabular}

\footnotetext{
'Means tested social assistance receipt.

ii Low: $1^{\text {st }}$ quantile; Medium: $2-4^{\text {th }}$ quantile: High: $5^{\text {th }}$ quantile.
} 
Table A2. Balance Table Women.

\begin{tabular}{|c|c|c|c|c|c|c|c|}
\hline \multirow[b]{2}{*}{ Variable } & \multirow[b]{2}{*}{ Sample } & \multicolumn{2}{|c|}{ Mean } & \multirow[b]{2}{*}{$\%$ bias } & \multirow{2}{*}{$\begin{array}{l}\% \text { red. } \\
\mid \text { bias } \mid\end{array}$} & \multicolumn{2}{|c|}{ Variance } \\
\hline & & Treated & Contr. & & & Treated & Contr. \\
\hline \multicolumn{8}{|c|}{ Socio-demographic background and year of birth: } \\
\hline \multirow[t]{2}{*}{ Born 1985 (ref:1980) } & Unmatched & 0.503 & 0.506 & -0.5 & & 0.71 & 0.71 \\
\hline & Matched & 0.503 & 0.506 & -0.5 & -0.2 & 0.71 & 0.71 \\
\hline \multirow{2}{*}{$\begin{array}{l}\text { Two parents (ref: } \\
\text { single parent) }\end{array}$} & Unmatched & 0.568 & 0.744 & -37.5 & & 0.70 & 0.66 \\
\hline & Matched & 0.568 & 0.562 & 1.4 & 96.2 & 0.70 & 0.70 \\
\hline \multirow[t]{2}{*}{ Other family type } & Unmatched & 0.021 & 0.006 & 13 & & 0.38 & 0.28 \\
\hline & Matched & 0.021 & 0.022 & -0.8 & 93.7 & 0.38 & 0.37 \\
\hline \multirow{2}{*}{$\begin{array}{l}\text { Low parent educ. (ref: } \\
\text { not low) }\end{array}$} & Unmatched & 0.200 & 0.104 & 27 & & 0.63 & 0.55 \\
\hline & Matched & 0.200 & 0.195 & 1.2 & 95.4 & 0.63 & 0.63 \\
\hline \multirow{2}{*}{$\begin{array}{l}\text { Native, both parents } \\
\text { native (ref: immi. age }>12 \text { ) }\end{array}$} & Unmatched & 0.824 & 0.865 & -11.3 & & 0.62 & 0.58 \\
\hline & Matched & 0.824 & 0.827 & -0.9 & 92.3 & 0.62 & 0.62 \\
\hline \multirow{2}{*}{$\begin{array}{l}\text { Native, } \geq 1 \text { parent } \\
\text { Immigrant }\end{array}$} & Unmatched & 0.054 & 0.043 & 5.5 & & 0.48 & 0.45 \\
\hline & Matched & 0.054 & 0.053 & 0.4 & 92.1 & 0.48 & 0.48 \\
\hline \multirow[t]{2}{*}{ Immigration age $\leq 12$} & Unmatched & 0.088 & 0.073 & 5.5 & & 0.53 & 0.51 \\
\hline & Matched & 0.088 & 0.086 & 0.8 & 85.3 & 0.53 & 0.53 \\
\hline \multicolumn{8}{|l|}{ Social problems in parents: } \\
\hline \multirow{2}{*}{$\begin{array}{l}\text { 1-2 years with fam. } \\
S A^{i} \text { age } 8-17 \text { (ref: } 0 \text { yrs) }\end{array}$} & Unmatched & 0.497 & 0.742 & -52.1 & & 0.71 & 0.66 \\
\hline & Matched & 0.497 & 0.494 & 0.5 & 99 & 0.71 & 0.71 \\
\hline \multirow{2}{*}{$\begin{array}{l}3+\text { years with fam. } \\
\text { SA age 8-17 }\end{array}$} & Unmatched & 0.164 & 0.107 & 16.8 & & 0.61 & 0.56 \\
\hline & Matched & 0.164 & 0.164 & -0.1 & 99.5 & 0.61 & 0.61 \\
\hline \multirow{2}{*}{$\begin{array}{l}\geq 1 \text { cust. sentence in } \\
\text { parents, age } 0-17 \text { (ref: 0) }\end{array}$} & Unmatched & 0.096 & 0.036 & 24.2 & & 0.54 & 0.43 \\
\hline & Matched & 0.096 & 0.096 & -0.1 & 99.5 & 0.54 & 0.54 \\
\hline \multicolumn{8}{|c|}{ School performance and choice: } \\
\hline \multirow{2}{*}{$\begin{array}{l}\text { Medium grades (ref: low } \\
\text { grades) }\end{array}$} & Unmatched & 0.340 & 0.545 & -42.1 & & 0.69 & 0.71 \\
\hline & Matched & 0.340 & 0.337 & 0.7 & 98.3 & 0.69 & 0.69 \\
\hline \multirow[t]{2}{*}{ High grades } & Unmatched & 0.067 & 0.304 & -64.1 & & 0.50 & 0.68 \\
\hline & Matched & 0.067 & 0.066 & 0.2 & 99.7 & 0.50 & 0.50 \\
\hline \multirow[t]{2}{*}{ Grades, no info. } & Unmatched & 0.024 & 0.010 & 11 & & 0.39 & 0.32 \\
\hline & Matched & 0.024 & 0.025 & -0.2 & 97.8 & 0.39 & 0.39 \\
\hline \multirow{2}{*}{$\begin{array}{l}\text { Vocational track (ref: } \\
\text { academic) }\end{array}$} & Unmatched & 0.480 & 0.462 & 3.6 & & 0.71 & 0.71 \\
\hline & Matched & 0.480 & 0.486 & -1.3 & 65 & 0.71 & 0.71 \\
\hline \multirow[t]{2}{*}{ Ind. program } & Unmatched & 0.321 & 0.034 & 81.2 & & 0.68 & 0.42 \\
\hline & Matched & 0.321 & 0.319 & 0.6 & 99.2 & 0.68 & 0.68 \\
\hline Health: & & & & & & & \\
\hline Ever hospital care (ref: & Unmatched & 0.073 & 0.037 & 15.5 & & 0.51 & 0.44 \\
\hline no) & Matched & 0.073 & 0.066 & 3 & 80.4 & 0.51 & 0.50 \\
\hline Previous convictions: & & & & & & & \\
\hline Pre-treatment & Unmatched & 0.006 & 0.002 & 22 & & 0.15 & 0.11 \\
\hline conv. month 1-12 (ref: 0) & Matched & 0.006 & 0.006 & 1.2 & 94.3 & 0.15 & 0.15 \\
\hline Pre-treatment & Unmatched & 0.005 & 0.001 & 17.9 & & 0.16 & 0.11 \\
\hline conv. month $13-21$ & Matched & 0.005 & 0.005 & 2.1 & 88.2 & 0.16 & 0.15 \\
\hline
\end{tabular}

\footnotetext{
'Means tested social assistance receipt.

ii Low: $1^{\text {st }}$ quantile; Medium: $2-4^{\text {th }}$ quantile: High: $5^{\text {th }}$ quantile.
} 
Table 1. Results from PSM. ${ }^{\text {a } 1-1 ~ n e a r e s t ~ n e i g h b o r ~ m a t c h i n g . ~ T r e a t e d ~ m e n: ~ 3,266 ; ~ w o m e n: ~}$ 3,198. Outcome Is Crime Rate During the Follow-Up Period.

\begin{tabular}{|c|c|c|c|c|c|c|}
\hline & Sample & Treated & Controls & Difference & S.E. & T-stat \\
\hline & & & MEN & & & \\
\hline Crime rate & Unmatched & 0.276 & 0.069 & 0.208 & 0.005 & 44.63 \\
\hline \multirow[t]{2}{*}{ after window } & Matched (ATT) & 0.276 & 0.136 & 0.140 & 0.036 & 3.94 \\
\hline & & & WOMEN & & & \\
\hline Crime rate & Unmatched & 0.060 & 0.016 & 0.044 & 0.002 & 18.37 \\
\hline after window & Matched (ATT) & 0.060 & 0.036 & 0.024 & 0.021 & 1.13 \\
\hline
\end{tabular}

${ }^{\mathrm{a}}$ Explanatory factors in logit on dropout for propensity score estimation: convictions prior to dropout window; final grades from compulsory school; family type at age 16; parents' educational level; ethnic background; means-tested social assistance benefits for parents; incarceration of parents; hospital stays up until dropout window; birth cohort; high school track. 
Table 2. Relative Hazard Rates for First Conviction After Dropout Window, Matched Sample, Men: $\mathrm{N}$ (subjects) $=6,433 ; \mathrm{N}$ (failures) $=2,484 ; \mathrm{N}(\mathrm{obs})=98,954$.

\begin{tabular}{|c|c|c|c|c|}
\hline & 1 & 2 & 3 & 4 \\
\hline \multicolumn{5}{|c|}{ Time-stable covariate: } \\
\hline Non-dropouts & 1 & 1 & 1 & 1 \\
\hline Dropouts & $1.54 * * *$ & $1.45^{* * *}$ & $1.20 * * *$ & $1.14^{* *}$ \\
\hline \multicolumn{5}{|c|}{ Time-varying covariates: } \\
\hline CLF & & 1 & & 1 \\
\hline ULF & & 1.06 & & 1.08 \\
\hline Students & & 1.00 & & 0.96 \\
\hline Inactive & & $1.52 * * *$ & & $1.40 * * *$ \\
\hline No diploma & & & 1 & 1 \\
\hline Diploma & & & $0.44^{* * *}$ & $0.46^{* * *}$ \\
\hline$-\mathrm{LL}$ & 7524.04 & 7499.63 & 7437.99 & 7419.52 \\
\hline
\end{tabular}


Figure 1. Convictions by Month, Before and After Dropout Window (Year 2 in High

School): Unmatched Sample for Men and Women, 3-Year Moving Average.
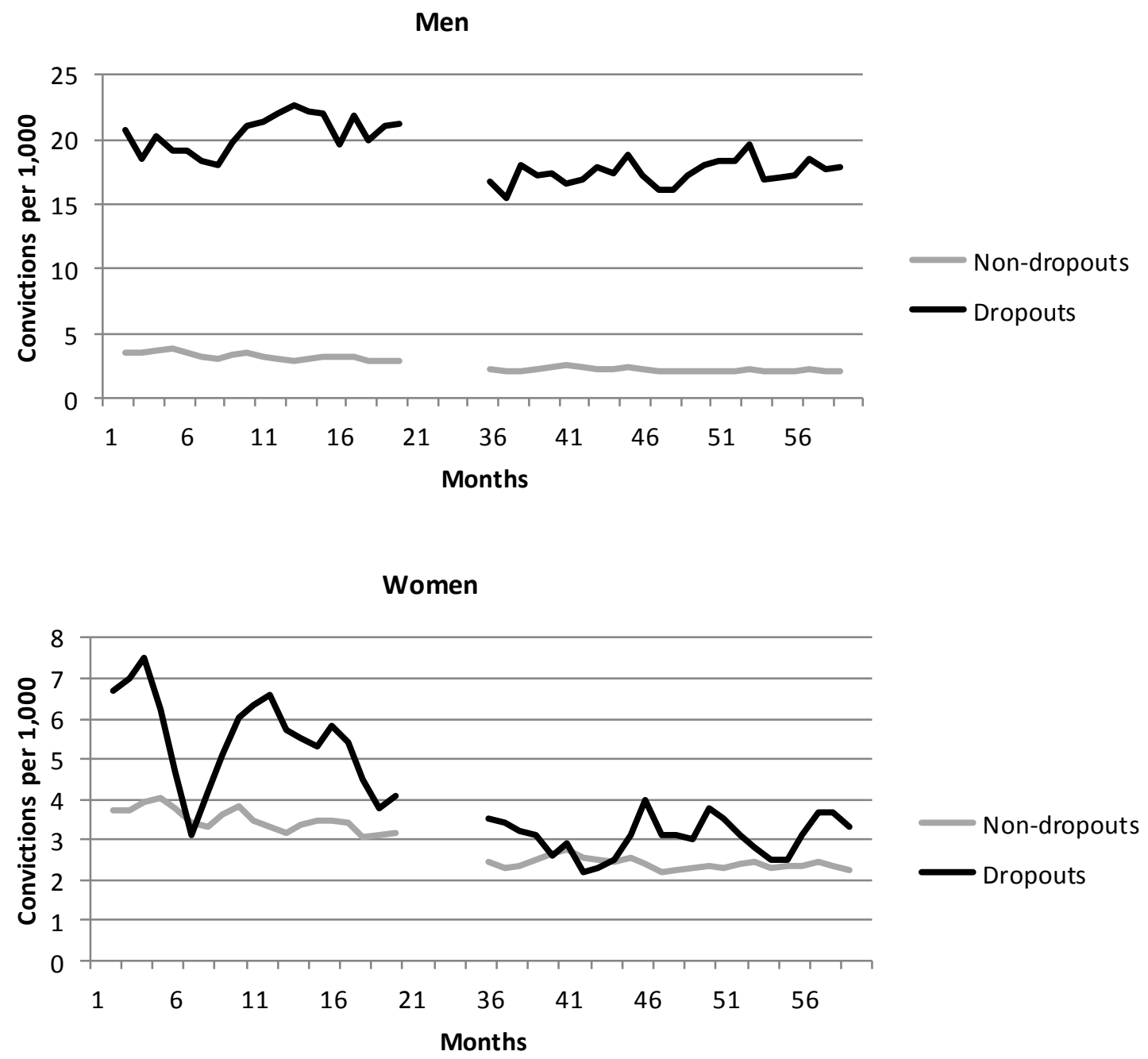
Figure 2. Convictions by Month, Before and After Dropout Window: Matched Sample, 3Year Moving Average.

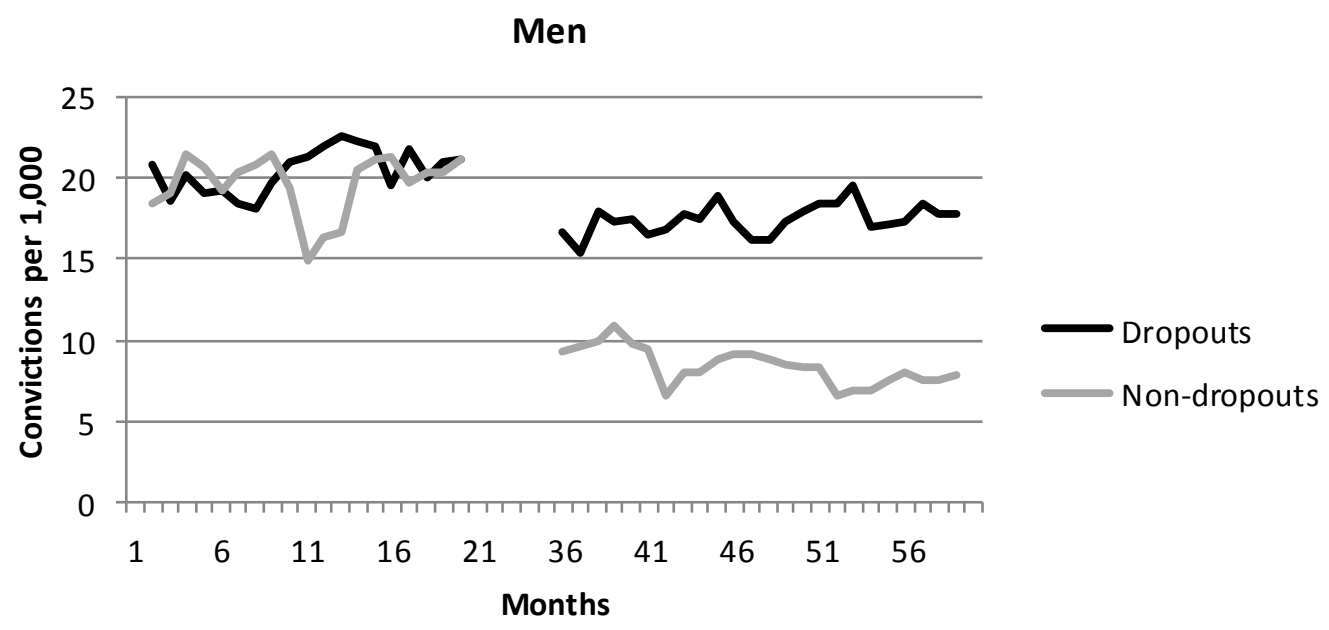

Women

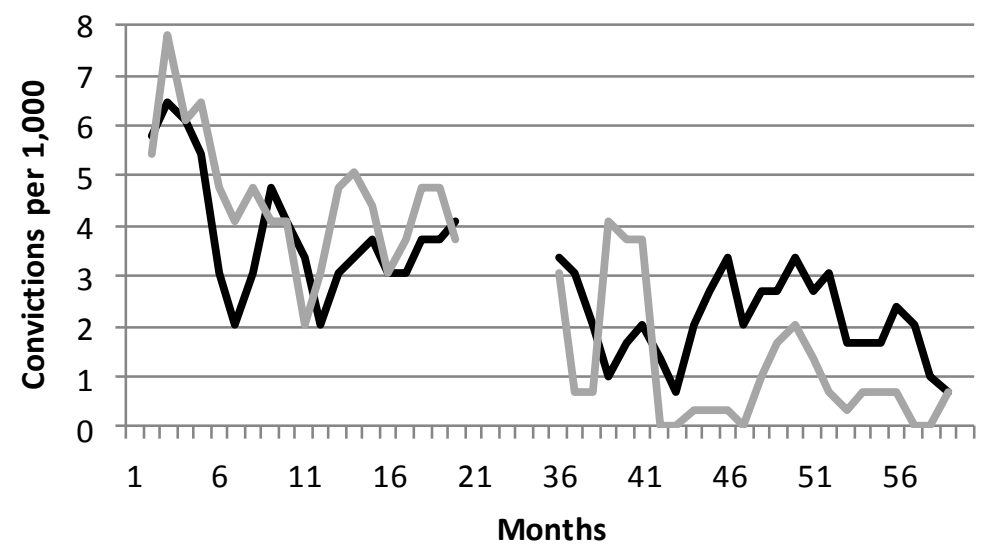


Figure 3. Baseline Hazard Rate for Criminal Conviction Over Months Since Dropout Window.

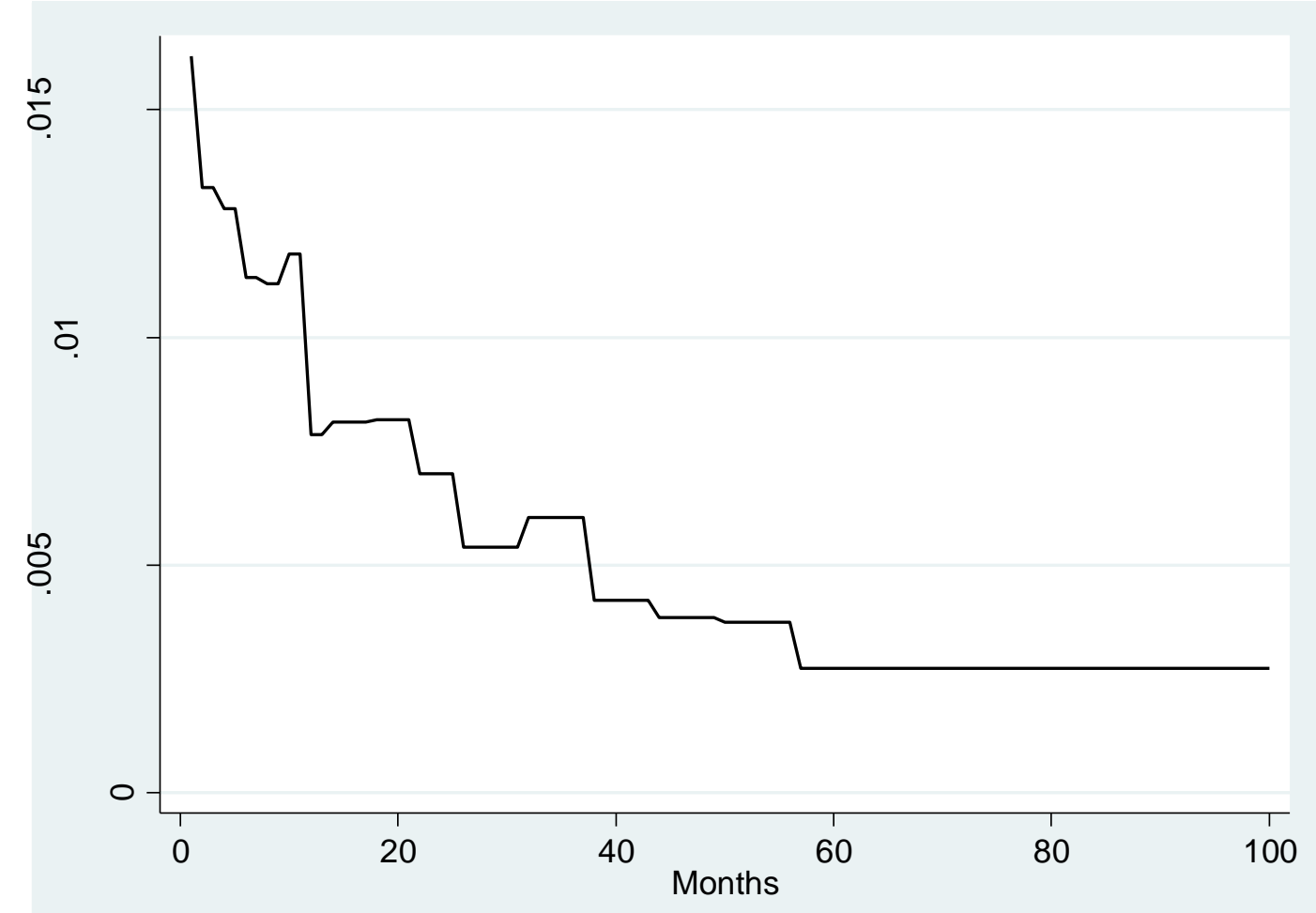

